\title{
Clinical and Radiological Outcome of a new Total Cervical Disc Replacement Design
}

\section{Journal Article}

\section{Author(s):}

Mehren, Christoph; Heider, Franziska; Sauer, Daniel; Kothe, Ralph; Korge, Andreas; Hitzl, Wolfgang; Würtz-Kozak, Karin (D)

Publication date:

2019-02-15

Permanent link:

https://doi.org/10.3929/ethz-b-000280385

Rights / license:

In Copyright - Non-Commercial Use Permitted

Originally published in:

Spine 44(4), https://doi.org/10.1097/brs.0000000000002799 
SPINE An International Journal for the study of the spine, Publish Ahead of Print

DOI: $10.1097 / B R S .0000000000002799$

\section{Clinical and Radiological Outcome of a new Total Cervical Disc Replacement Design}

Christoph Mehren MD ${ }^{1,2}$; Franziska Heider $\mathrm{MD}^{1,2}$; Daniel Sauer MD ${ }^{1,2}$; Ralph Kothe MD ${ }^{3,4}$; Andreas Korge $\mathrm{MD}^{1,2}$; Wolfgang Hitzl MD PhD ${ }^{5,6}$; Karin Wuertz-Kozak MD PhD ${ }^{1,2,7,8}$

${ }^{1}$ Schön Klinik München Harlaching Spine Center, Munich, Germany

${ }^{2}$ Academic Teaching Hospital and Spine Research Institute, Paracelsus Medical University, Salzburg, Austria

3 Schön Klinik Eilbeck

Clinic for Spinal Surgery, Hamburg, Germany

${ }^{4}$ Department of Orthopedics,

University Medical Center Hamburg-Eppendorf, Hamburg, Germany

${ }^{5}$ Research Office - Biostatistics, Paracelsus Medical University, Salzburg, Austria

${ }^{6}$ Department of Ophthalmology and Optometry, Paracelsus Medical University, Salzburg, Austria

${ }^{7}$ Institute for Biomechanics, ETH Zurich, Zurich, Switzerland

${ }^{8}$ Department of Health Sciences, University of Potsdam, Potsdam, Germany 


\section{Corresponding Author}

Dr. Christoph Mehren

Schön Clinic Munich Harlaching

Academic Teaching Hospital Paracelsus Medical University Salzburg Harlachinger Str. 51

81547 Munich Germany

Tel: +49 89 6211-2011

Fax: +49 89 6211-2012

CMehren@schoen-kliniken.de

The device(s)/drug(s) that is/are the subject of this manuscript is/are not FDA-approved for this indication and is/are not commercially available in the United States.

No funds were received in support of this work.

No relevant financial activities outside the submitted work. 
Abstract

Study design: Non-randomized prospective and single center clinical trial of the ProDisc Vivo prosthesis.

Objective: Investigate the clinical and radiological results of a refined cTDR - the ProDisc Vivo with two years of follow up (FU). The incidence of implant-related complications was recorded as a secondary outcome variable.

Summary of Background Data: Previous generations of the ProDisc artificial cervical disc replacement generate high primary stability due to keel-based designs with opening of the anterior cortex during the implantation and subsequent high rates of heterotopic ossifications.

Methods: Clinical outcome scores included the Neck Disability Index (NDI), Visual Analogue Scale (VAS), arm and neck pain self-assessment questionnaires. The radiological outcome included the range of motion (ROM) and the occurrence of heterotopic ossifications. The incidence of implant-related complications with new implant design was recorded as a secondary outcome variable.

Results: A total of 55 patients received a single level treatment with the ProDisc Vivo cTDR between C3/4 and C6/7, with a follow up rate of 78\%. The clinical outcome scores improved in all parameters significantly ( $\mathrm{p}=0.0001$ ) (NDI: $68.3 \rightarrow 17.4$; VAS arm: $6.3 \rightarrow 1.4$; VAS neck: 4.9 $\rightarrow 1.6)$. The ROM of the index-segment didn't show a significant change $(\mathrm{p}=0.26)\left(7.9^{\circ} \rightarrow\right.$ $9.2^{\circ}$ ). Heterotopic ossifications at the index segment was found as grade 0 in $58 \%$, grade 1 in $22 \%$, grade 2 in $10 \%$, grade 3 (with functional impairment of the prosthesis) in $7 \%$ and grade 4 in $3 \%$ of the cases. We observed three implant-related complications (5.5\%), with two implant dislocations anteriorly and one low-grade infect.

Copyright @ 2018 Wolters Kluwer Health, Inc. Unauthorized reproduction of this article is prohibited. 
Conclusion: cTDR with ProDisc Vivo demonstrated a significant and sustained improvement of all clinical outcome parameters. A less-invasive implantation mechanism with lower primary stability of the cTDR might be a reason for a higher dislocation rate compared to the keel-based previous generation ProDisc C.

Key Words: Total Disc Replacement; Total Disc Arthroplasty; ProDisc Vivo; heterotopic ossifications; implant-related complications; Outcomes

\section{Level of Evidence: 4}




\section{Introduction}

Total cervical disc replacement (cTDR) has been established as a viable treatment option for a variety of pathologies, such as symptomatic cervical disc disease or soft disc herniation with radiculopathy. Clinical studies have demonstrated this procedure to be a safe and suitable treatment alternative to the gold standard, anterior cervical discectomy and fusion (ACDF) [1-9].

Since the first introduction of cTDRs, design characteristics and material being used have undergone extensive changes. Initial designs were created with a focus on ensuring primary stability, but employed extensive fixations with screws (e.g. PrestigeST, Medtronic Sofamor Danek, Memphis, TN) or required excessive preparation of the implant site (Bryan Disc, Medtronic Sofamor Danek, Memphis, TN). These designs resulted in technically demanding, time-consuming implantation processes and bared a risk for heterotopic ossifications due to opening of the cortical structures $[10,11]$. Thus, subsequent cTDR designs aimed to simplify the implantation while circumventing the need to open the cortical structures. Furthermore, surface coatings (e.g. plasma-sprayed titanium or hydroxyapatite surface modifications) were introduced to enhance bony ingrowth and thus ensure long-term fixation [12].

The ProDisc Vivo (DePuy Synthes, West Chester, PA, USA) consists of two titanium alloy endplates for improved MRI compatibility and a fixed, ultra-high molecular weight polyethylene (UHMWPE) core on cobalt-chrome-molybdenum alloy articulation, which provides motion in all axes in a semi-constrained fashion for flexion/extension and lateral bending. Primary stability is provided with teeth fixation at each endplate. The superior plate has a convex design for better anatomical fixation as demonstrated in Figure 1. A trapezoidal footprint design should provide optimal anatomical fit and maximum endplate coverage. Long-term stability is provided by a plasma-sprayed titanium surface, which is intended to promote secondary bony ingrowth.

The aim of this study was to verify the clinical effectiveness of the third design generation of the ProDisc - the ProDisc Vivo - with 2 years follow-up (FU) and to evaluate their radiologic outcome, including implant specific complications. 


\section{Materials and Methods}

\section{Study design}

Within the framework of a prospective, non-randomised study at a single large spine center, all patients who were treated on a single level between C3 and C7 with a ProDisc Vivo ${ }^{\mathrm{TM}}$ artificial disc prosthesis between 03/2012 and 03/2015 were consecutively included in this study following their written consent. The investigation included preoperative data as well as 3, 12 and 24 months FU results and was approved by the internal ethics committee.

The inclusion and exclusion criteria of this study were clearly defined prior to the initiation of this study (Table 1). Primary inclusion criteria included cervical degenerative disc disease and clinical symptoms of nerve root compression associated with intractable radiculopathy with and without neurological deficits between the levels C3/4 and C6/7, which had proven unresponsive to non-operative treatment.

Clinical and socio-economic outcome parameters were determined by means of self-assessment questionnaires that were completed by all patients individually: NDI (Neck Disability Index), VAS (Visual Analog Score) arm pain and VAS neck pain. Standardized questions relating to patient satisfaction and employment status were likewise completed at each time point.

Radiological examinations entailed X-Ray images of the cervical spine in 2 planes as well as flexion/extension images. Measurements of the prosthesis range of motion (ROM) as well as of the adjacent segments disc space heights were performed with Impax software (IMPAX EE, Agfa Healthcare N.V.).

The extent of heterotopic ossifications (HO) was graded according to the modified McAfee classification system for lumbar disc prostheses as previously described by Mehren/Suchomel et al. (Table 2) [13].

\section{Implant and surgical technique}

The ProDisc Vivo ${ }^{\mathrm{TM}}$ implant, which was used exclusively in this study, is the third generation of a metal-on-polyethylene, ball-and-socket type articulating device. The implant was inserted enbloc as a one-piece device. 
A right-sided anterolateral, microsurgically modified approach was routinely used as previously described [14].

The discectomy and decompression of the spinal canal was performed with the assistance of a surgical microscope.

The midline was marked under anteroposterior (AP) fluoroscopy. The segment was held in distraction by retaining screws. A trial implant with the appropriate footprint and height was adequately placed in the intervertebral space, which was followed by the final insertion of the device into the prepared disc space. Bone wax was used to seal the holes of the retaining screws. In postoperative care, a soft collar was used until wound healing was completed. Non-steroidal anti-inflammatory medication was not used routinely.

\section{Statistical analysis}

Data consistency were checked and data were screened for outliers and normality by using quantile plots. Pearson's Chi-Square test was used to analyze crosstabulations tables. A repeated measures ANOVA model with paired Student t-tests as post-hoc tests were used to compare means over time. Whisker plots with $95 \%$ confidence intervals were used to illustrate results. Pearson's correlation coefficients were computed and tested. All tests were performed two-sided, and p-values $<0.05$ were considered as statistically significant. All statistical analyses in this report were performed by use of STATISTICA 13 (Hill, T. \& Lewicki, P. Statistics: Methods and Applications. StatSoft, Tulsa, OK).

\section{Results}

Patient characteristics

A total of 55 patients met the inclusion criteria for a single level treatment between C3/4 and C6/7. The average age of included patients was 44.2 years (range 30-62 years) with relatively equal gender distribution (31f, 24m). Treated levels are outlined in Table 3.The Follow up rate at the 2 years $\mathrm{FU}$ was $78.2 \%(\mathrm{n}=43)$. 


\section{Clinical outcome scores}

Mean NDI improved significantly over the study duration, from $68.3 \pm 11.0$ points preoperatively to $24.4 \pm 12.4$ points at 12 months $(\mathrm{p}<0.0001)$ and $17.4 \pm 11.4$ points at 24 months FU ( $<<0.0001)$. The improvement between 12 and 24 months FU was also statistically significant $(\mathrm{p}<0.0001)$ (Figure 2).

Similarly, VAS arm and VAS neck pain also improved over the course of the observation period from a pre-operative mean of $6.3 \pm 1.9$ and $4.9 \pm 2.3$ to $1.8 \pm 0.9$ and $1.8 \pm 1.1$ at the 12 months and $1.4 \pm 0.9$ (Figure 3) and $1.6 \pm 1.0$ (Figure 4), respectively at 24 months $\mathrm{FU}(\mathrm{p}<0.00001)$. In contrast to the NDI, no significant difference was observed between 12 and 24 months FU ( $p=0.09$ resp. $p=0.36$ ). This improvement of VAS and NDI during the post-operative course was reflected by high patient satisfaction rates: 93\% ( $\mathrm{n}=40 / 43)$ of patients reported a highly satisfactory outcome at the 24 months FU examination and $2.3 \%(n=1 / 43)$ a satisfactory outcome. One of the remaining patients was not satisfied and the other patient did not wish to provide this subjective outcome evaluation.

\section{Radiological findings}

The index segment revealed a preoperative mean range of motion (ROM) of $7.9^{\circ} \pm 4.5^{\circ}$. During the subsequent post-operative course, the ROM increased to $9.6^{\circ} \pm 5.3^{\circ}$ and $9.2^{\circ} \pm 4.6^{\circ}$ in mean at the 12 and 24 months FU examination respectively (Figure 5). This change in the mean ROM of the index segment was statistically not significant $(\mathrm{p}=0.23)$.

The incidence and severity of $\mathrm{HO}$ at the 24 months $\mathrm{FU}$ is outlined in Figure 6: Grade 0 ossification was observed in 58\%, grade 1 in $22 \%$, grade 2 in $10 \%$, grade 3 (with functional impairment of the prosthesis) in $7 \%$ of cases and grade 4 (with solid fusion of the index segment) in $3 \%$ of cases.

The occurrence of $\mathrm{HO}$ did not significantly affect the clinical outcome at the last FU (NDI: $\mathrm{p}=0.989$; VAS arm: $\mathrm{p}=0.417$; VAS neck: $\mathrm{p}=0.859$ ). 


\section{Complications}

Dislocation of the whole implant anteriorly was observed in two C3/4-treated cases. One patient had to be revised within the first post-operative week, necessitating implant removal and interbody fusion with a cage as demonstrated in Figure 7. The other implant dislocation was observed at the 3 months FU. Although the indication for revision was given, the patient denied any further intervention and was lost to follow up.

Another patient presented with persisting neck pain and signs of severe osteolysis (CT scans), indicating low grade infection, and was revised after the 12 months FU. After implant removal and fusion with a cage, the histological investigation confirmed bacterial infection. Neck pain improved after the revision surgery.

\section{Discussion}

The effectiveness of cTDRs has been under investigation for many years. Numerous studies have demonstrated that CTDR and ACDF achieved comparatively similar improvements in clinical outcome parameters $[3,4,8,9,15,16]$, which was confirmed by a systematic review that investigated disability, pain, general state of health, neurological success and satisfaction [17]. Importantly, a number of studies demonstrated that at short- and mid-term FUs, the rates of postoperative revision surgeries were significantly lower for cTDRs than for ACDF's $[3,5,18,19]$.

Over the years, numerous cTDR designs have been developed, with the goal to facilitate the implantation while obtaining sufficient primary stability. Independent of the type and design of the prosthesis, reports consistently describe a significant improvement of the clinical parameter over time [8, 19-24], even at longer FUs [2, 4, 18, 25, 26]. The herein presented first report on the outcomes of the Prodisc Vivo is hence in line with previous reports on other cTDRs, with a significant improvement of NDI, VAS arm and VAS neck at all post-operative stages in comparison to baseline levels.

While clinical parameters constitute the primary readout after CTDR, the measurement of range of motion (ROM) can provide valuable information on functionality. However, up to now, there is no consensus about the "needed" ROM to provide a load-sharing function to the adjacent 
segment. Within this cohort, we observed a non-significant increase of ROM of the index segment from $7.9^{\circ}$ preoperatively to $9.6^{\circ}$ and $9.2^{\circ}$ at 12 and 24 months FU, respectively. In the literature, comparable values can be found for other prosthesis designs. Coric et al. [20] reported an increase of ROM from $8.2^{\circ}$ (preoperatively) to $9.8^{\circ}$ (2 year FU) for another keel-based device, the Kineflex C. Further examples of the ROM at 2 years FU are $7.7^{\circ}$ for the Prestige ST [27], $7.9^{\circ}$ for the Discover [28], $10^{\circ}$ for the Mobi-C [19] and 8.4 $4^{\circ}$ for the ProDisc C [21] and at a slightly lower range, $6.5^{\circ}$ for the Bryan Disc [22] and $5.7^{\circ}$ for the PCM [29], but still the radiological success-rate with an implant ROM in flexion and extension with more than $2^{\circ}$ was indicated with $98.9 \%$.

Despite overall good outcomes of cTDRs, including the ProDisc Vivo (as demonstrated herein), certain complications may arise. These are closely related to the implantation mechanism and the primary stability features of the device. Only a few case reports exist that describe vertebral split fractures after keel based cTDR [20, 30, 31], but with less invasive fixation mechanisms, the risk should be lower. The "non-keel” ProDisc Vivo provides the primary stability with anatomically configurated endplates and 6 spikes at each endplate. In fact, no such cases of vertebral split fractures occurred in this cohort, neither immediately nor during the FU. However, we were faced with two (3.6\%) early anterior implant dislocations (both in the segment C3/4), likely due to insufficient posterior preparation/release in combination with initial too far anterior positioning of the device. Despite being a non-keel device, these rates are only slightly higher than for typical keel-based TDRs used in comparable cohorts with similar inclusion criterias, such as the Kineflex-C (2/136 at 2 years FU) [20] or the first generation of the ProDisc design, the ProDisc C with zero out of 103 at 5 years FU and one out of 70 at 10 years FU [25, 32]. Burkus et al. [2] reported about one implant dislocation out of 256 Prestige ST prosthesis with an additional anterior transcortical fixation mechanism. Typically, higher rates of implant dislocation even in short term FU are reported for non-keel based/short teeth fixation designed devices. For example Shi et al. [28] reported for the Discover prosthesis, used in single level cases as well, an implant migration in 10 out of 60 (16.7\%) implanted levels, with an additional two cases (3.3\%) with implant subsidence. In summary, the risk of implant subsidence and implant migration seemed to be slightly higher for the devices without an additional anterior or vertebral fixation mechanism (i.e. for non-keel devices) even in the short term follow up. Nevertheless, a sufficient posterior release with resection of the posterior longitudinal ligament 
and physiological opening of the intervertebral disc space without pathological segmental lordosis and a proper implant positioning in combination with an adequate implant footprint is definitely essential to prevent anterior migration.

Aside from implant dislocation, high-grade $\mathrm{HO}$ at the index segment (up to solid fusion, i.e. Grade 4) constitutes an important unintended outcome of cTDRs, affecting the motion and possibly resulting in loss of function of the implanted device [33-35]. Different cTDR designs were shown to result in different $\mathrm{HO}$ rates: $\mathrm{Yi}$ et al. [36] compared the keel-based first generation of the ProDisc (ProDisc C) with the Bryan Disc and found HO rates of $71.4 \%(n=28)$ and $21.0 \%(n=81)$ at 12 months FU, respectively; Mehren et al. [37] reported comparable high numbers for the ProDisc C. Other keel-based prosthesis also showed a relatively high incidence of HO, such as $23.8 \%$ (Grade 3 and 4) for the Mobi-C cervical disc prosthesis after 4 years FU, with progression over time [19]. However, HO rates seem to be generally lower for designs that abstain from opening of the anterior cortex or extensive graft bed preparation during the implantation procedure. The PCM total disc prostheses demonstrated Grade 3 HO rates of only 3.3\% and Grade $4 \mathrm{HO}$ rates of only $1.1 \%$ after 2 years FU [29]. In the herein presented cohort operated with the ProDisc Vivo, 7\% showed Grade 3 HO and 3\% Grade 4 HO after 2 years. Although further studies with comparable cohorts, comparable follow ups, diagnostics (x-ray or CT scan) and postoperative care are needed to verify these findings, our data supports the postulated hypothesis that $\mathrm{HO}$ occurrence may be related to the preparation of the end plates as well as the opening of the cortex $[10,11]$.

\section{Study limitations:}

One of the limitations of this present investigation is a potential selection bias, which may be attributed to the fact that the data are derived from a non-randomised case series. In addition, a longer follow up is needed to capture the rate of implant-loosening due to insufficient ingrowth of the device.

\section{Conclusion}

We herein present the first study evaluating the clinical and radiological outcome of ProDisc Vivo, a novel cTDR. Similar to other cTDRs, the ProDisc Vivo device demonstrated a high clinical success-rate during the 2 years FU. The absence of keels in the ProDisc Vivo represents 
a substantial design change with the "ProDisc family" that eliminates the need of opening of the anterior cortex and reduces HO rates. Although such prostheses types with less-invasive implantanchoring can have higher risks of implant dislocation, this occurred only in $3 \%$ of cases for the ProDisc Vivo and hence only marginally more often than described for keel devices.

Even if the anticipated profit of CTDR in the sense of a reduced incidence of adjacent segment disease is still in a controversial discussion, at least a correct and sufficient movement of the cTDR is a crucial requirement. Thus, further developments of HO-avoiding strategies (implant design, fixation mechanism and postoperative care) are essential.

In the short term follow up the key to clinical success and improvement of the outcome parameters especially in radicular arm pain is certainly the basic operative technique of sufficient decompression of the neural structures instead of the total disc prosthesis itself. Obviously, a correct placement of the prosthesis and a steady low rate of implant-related complications is a prerequisite of sustainable good clinical outcomes, which should be verified in further studies with longer follow up durations.

Copyright @ 2018 Wolters Kluwer Health, Inc. Unauthorized reproduction of this article is prohibited. 


\section{References}

1. Delamarter RB, Zigler J (2012) Five-year Reoperation Rates, Cervical Total Disc Replacement versus Fusion, Results of a Prospective Randomized Clinical Trial. Spine (Phila Pa 1976) 38:1. doi: 10.1097/BRS.0b013e3182797592

2. Burkus JK, Haid RW, Traynelis VC, Mummaneni P V (2010) Long-term clinical and radiographic outcomes of cervical disc replacement with the Prestige disc: results from a prospective randomized controlled clinical trial. J Neurosurg Spine 13:308-318. doi: 10.3171/2010.3.SPINE09513

3. Loumeau TP, Darden B V, Kesman TJ, et al. (2016) A RCT comparing 7-year clinical outcomes of one level symptomatic cervical disc disease (SCDD) following ProDisc-C total disc arthroplasty (TDA) versus anterior cervical discectomy and fusion (ACDF). Eur spine $\mathrm{J}$ Off Publ Eur Spine Soc Eur Spinal Deform Soc Eur Sect Cerv Spine Res Soc. doi: 10.1007/s00586-016-4431-6

4. Phillips FM, Geisler FH, Gilder KM, et al. (2015) Long-term Outcomes of the US FDA IDE Prospective, Randomized Controlled Clinical Trial Comparing PCM Cervical Disc Arthroplasty With Anterior Cervical Discectomy and Fusion. Spine (Phila Pa 1976) 40:674-683. doi: 10.1097/BRS.0000000000000869

5. Davis RJ, Kim KD, Hisey MS, et al. (2013) Cervical total disc replacement with the Mobi-C cervical artificial disc compared with anterior discectomy and fusion for treatment of 2level symptomatic degenerative disc disease: a prospective, randomized, controlled multicenter clinical trial. J Neurosurg Spine 19:532-45. doi: 10.3171/2013.6.SPINE12527

6. Coric D, Kim PK, Clemente JD, et al. (2013) Prospective randomized study of cervical arthroplasty and anterior cervical discectomy and fusion with long-term follow-up: results in 74 patients from a single site. J Neurosurg Spine 18:36-42. doi:

10.3171/2012.9.SPINE12555

Copyright @ 2018 Wolters Kluwer Health, Inc. Unauthorized reproduction of this article is prohibited. 
7. Davis RJ, Nunley PD, Kim KD, et al. (2015) Two-level total disc replacement with Mobi-C cervical artificial disc versus anterior discectomy and fusion: a prospective, randomized, controlled multicenter clinical trial with 4-year follow-up results. J Neurosurg Spine 22:1525. doi: 10.3171/2014.7.SPINE13953.Disclosure

8. Skeppholm M, Lindgren L, Henriques T, et al. (2015) The Discover artificial disc replacement versus fusion in cervical radiculopathy—a randomized controlled outcome trial with 2-year follow-up. Spine J 15:1284-1294. doi: 10.1016/j.spinee.2015.02.039

9. Vaccaro A, Beutler W, Peppelman W, et al. (2013) Clinical outcomes with selectively constrained SECURE-C cervical disc arthroplasty: two-year results from a prospective, randomized, controlled, multicenter investigational device exemption study. Spine (Phila Pa 1976) 38:2227-39. doi: 10.1097/BRS.0000000000000031

10. Tu T-H, Wu J-C, Huang W-C, et al. (2012) The effects of carpentry on heterotopic ossification and mobility in cervical arthroplasty: determination by computed tomography with a minimum 2-year follow-up. J Neurosurg Spine 16:601-609. doi: 10.3171/2012.3.SPINE11436

11. Yi S, Shin DA, Kim KN, et al. (2013) The predisposing factors for the heterotopic ossification after cervical artificial disc replacement. Spine J 13:1048-1054. doi: 10.1016/j.spinee.2013.02.036

12. Pham MH, Mehta VA, Tuchman A, Hsieh PC (2015) Material Science in Cervical Total Disc Replacement. Biomed Res Int 2015:719123. doi: 10.1155/2015/719123

13. Mehren C, Suchomel P, Grochulla F, et al. (2006) Heterotopic ossification in total cervical artificial disc replacement. Spine (Phila Pa 1976) 31:2802-2806. doi: 10.1097/01.brs.0000245852.70594.d5

14. Caspar W, Barbier DD, Klara PM (1989) Anterior cervical fusion and Caspar plate stabilization for cervical trauma. Neurosurgery 25:491-502.

15. Coric D, Kim PK, Clemente JD, et al. (2013) Prospective randomized study of cervical arthroplasty and anterior cervical discectomy and fusion with long-term follow-up: results 
in 74 patients from a single site. J Neurosurg Spine 18:36-42. doi:

10.3171/2012.9.spine12555

16. Upadhyaya CD, Wu J-C, Trost G, et al. (2012) Analysis of the three United States Food and Drug Administration investigational device exemption cervical arthroplasty trials. J Neurosurg Spine 16:216-228. doi: 10.3171/2011.6.SPINE10623

17. Zechmeister I, Winkler R, Mad P (2011) Artificial total disc replacement versus fusion for the cervical spine: A systematic review. Eur Spine J 20:177-184. doi: 10.1007/s00586-0101583-7

18. Delamarter RB, Zigler JE, Murrey DB, et al. (2012) Seven-Year Reoperation Rates: Results of a Prospective Randomized Clinical Trial: Cervical Total Disc Replacement Versus Fusion. Spine J 12:S96. doi: 10.1016/j.spinee.2012.08.268

19. Hisey MS, Bae HW, Davis RJ, et al. (2015) Prospective, Randomized Comparison of Cervical Total Disk Replacement Versus Anterior Cervical Fusion. J Spinal Disord Tech 28:237-243.

20. Coric D, Nunley PD, Guyer RD, et al. (2011) Prospective, randomized, multicenter study of cervical arthroplasty: 269 patients from the Kineflex|C artificial disc investigational device exemption study with a minimum 2-year follow-up. J Neurosurg Spine 15:348-358. doi: 10.3171/2011.5.SPINE10769

21. Murrey D, Janssen M, Delamarter R, et al. (2009) Results of the prospective, randomized, controlled multicenter Food and Drug Administration investigational device exemption study of the ProDisc-C total disc replacement versus anterior discectomy and fusion for the treatment of 1-level symptomatic cervi. Spine J 9:275-286. doi:

10.1016/j.spinee.2008.05.006

22. Heller JG, Sasso RC, Papadopoulos SM, et al. (2009) Comparison of BRYAN Cervical Disc Arthroplasty With Anterior Cervical Decompression and Fusion Clinical Trial. Spine (Phila Pa 1976) 34:101-107.

23. Meisel H-J, Jurák L, Antinheimo J, et al. (2016) Four-year results of a prospective single-arm

Copyright @ 2018 Wolters Kluwer Health, Inc. Unauthorized reproduction of this article is prohibited. 
study on 200 semi-constrained total cervical disc prostheses: Clinical and radiographic outcome. J Neurosurg Spine 25:556-565. doi: 10.3171/2016.3.SPINE15810

24. Miao J, Yu F, Shen Y, et al. (2014) Clinical and radiographic outcomes of cervical disc replacement with a new prosthesis. Spine J 14:878-883. doi: 10.1016/j.spinee.2013.07.439

25. Mehren C, Heider F, Siepe CJ, et al. (2017) Clinical and radiological outcome at 10 years of follow-up after total cervical disc replacement. Eur Spine J. doi: 10.1007/s00586-017-52046

26. Dejaegher J, Walraevens J, Loon J Van, Calenbergh F Van (2016) 10-year follow-up after implantation of the Bryan Cervical Disc Prosthesis. Eur Spine J. doi: 10.1007/s00586-016$4897-2$

27. Mummaneni P V, Amin BY, Wu JC, et al. (2012) Cervical artificial disc replacement versus fusion in the cervical spine: a systematic review comparing long-term follow-up results from two FDA trials. Evid Based Spine Care J 3:59-66. doi: 10.1055/s-0031-1298610

28. Shi S, Zheng S, Li X-F, et al. (2016) Comparison of 2 Zero-Profile Implants in the Treatment of Single-Level Cervical Spondylotic Myelopathy: A Preliminary Clinical Study of Cervical Disc Arthroplasty versus Fusion. PLoS One 11:e0159761. doi:

10.1371/journal.pone.0159761

29. Phillips FM, Lee JYB, Geisler FH, et al. (2013) A prospective, randomized, controlled clinical investigation comparing PCM cervical disc arthroplasty with anterior cervical discectomy and fusion: 2-year results from the US FDA IDE clinical trial. Spine (Phila Pa 1976) 38:907-918. doi: 10.1097/BRS.0b013e318296232f

30. Tu T-H, Wu J-C, Fay L-Y, et al. (2012) Vertebral body split fracture after a single-level cervical total disc replacement. J Neurosurg Spine 16:231-235. doi: 10.3171/2011.11.SPINE11210

31. Completo A, Nascimento A, Ramos A, Simoes J (2015) Failure analysis of C-5 after total disc replacement with ProDisc-C at 1 and 2 levels and in combination with a fusion cage: finite-element and biomechanical models. J Neurosurg Spine 22:639-646. doi:

Copyright @ 2018 Wolters Kluwer Health, Inc. Unauthorized reproduction of this article is prohibited. 


\subsection{1/2014.10.SPINE14217}

32. Zigler JE, Delamarter R, Murrey D, et al. (2012) ProDisc-C and ACDF as Surgical Treatment for Single Level Cervical Symptomatic Degenerative Disc Disease. Spine (Phila Pa 1976) 38:1. doi: 10.1097/BRS.0b013e318278eb38

33. Lee JH, Jung TG, Kim HS, et al. (2010) Analysis of the incidence and clinical effect of the heterotopic ossification in a single-level cervical artificial disc replacement. Spine J 10:676682. doi: 10.1016/j.spinee.2010.04.017

34. Lee SE, Chung CK, Jahng TA (2012) Early development and progression of heterotopic ossification in cervical total disc replacement. J Neurosurg Spine 16:31-36. doi: 10.3171/2011.8.SPINE11303

35. Kang KC, Lee CS, Han JH, Chung SS (2010) The factors that influence the postoperative segmental range of motion after cervical artificial disc replacement. Spine J 10:689-696. doi: 10.1016/j.spinee.2010.04.016

36. Yi S, Kim KN, Yang MS, et al. (2010) Difference in occurrence of heterotopic ossification according to prosthesis type in the cervical artificial disc replacement. Spine (Phila Pa 1976) 35:1556-1561. doi: 10.1097/BRS.0b013e3181c6526b

37. Mehren C, Suchomel P, Grochulla F, et al. (2006) Heterotopic ossification in total cervical artificial disc replacement. 


\section{Figure Legends}

Figure 1: The ProDisc Vivo artificial disc (from: https://emea.depuysynthes.com)
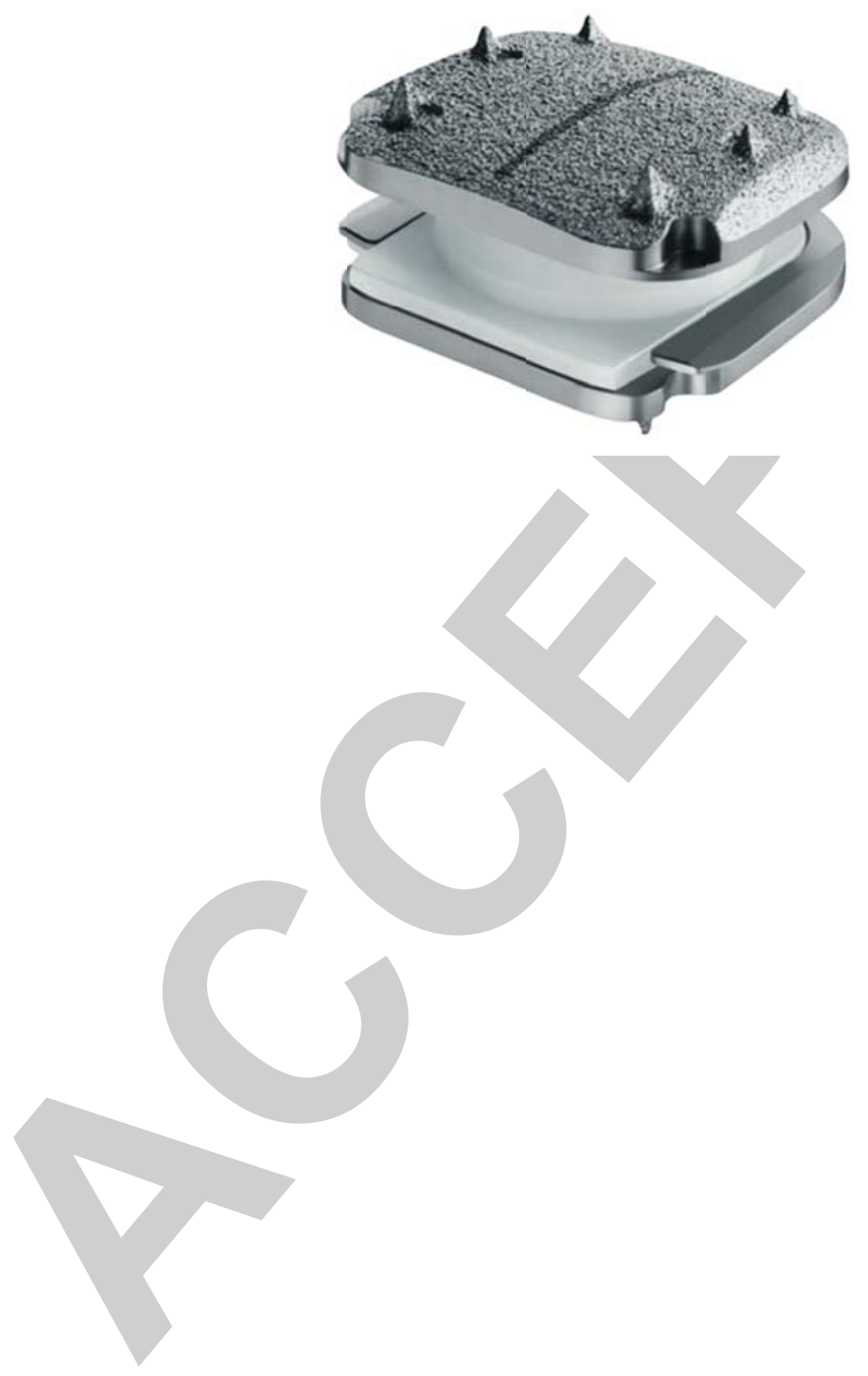

Copyright @ 2018 Wolters Kluwer Health, Inc. Unauthorized reproduction of this article is prohibited. 
Figure 2: Improvement of Neck Disability Index (NDI) over time, illustrated as Whisker plots with $95 \%$ confidence intervals.

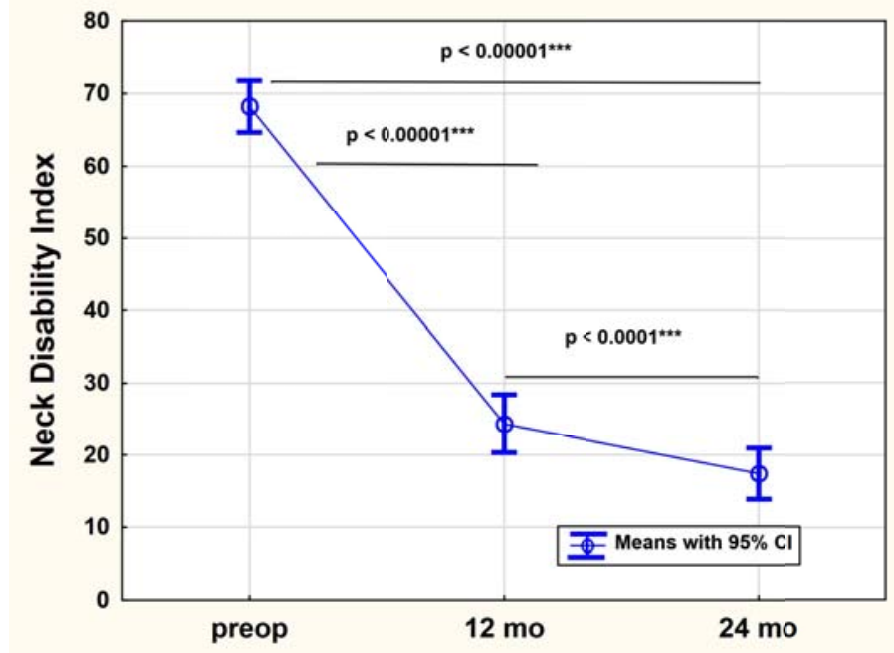

Copyright @ 2018 Wolters Kluwer Health, Inc. Unauthorized reproduction of this article is prohibited. 
Figure 3: Improvement of Visual Analog Scale (VAS) for arm pain over time, illustrated as Whisker plots with 95\% confidence intervals.

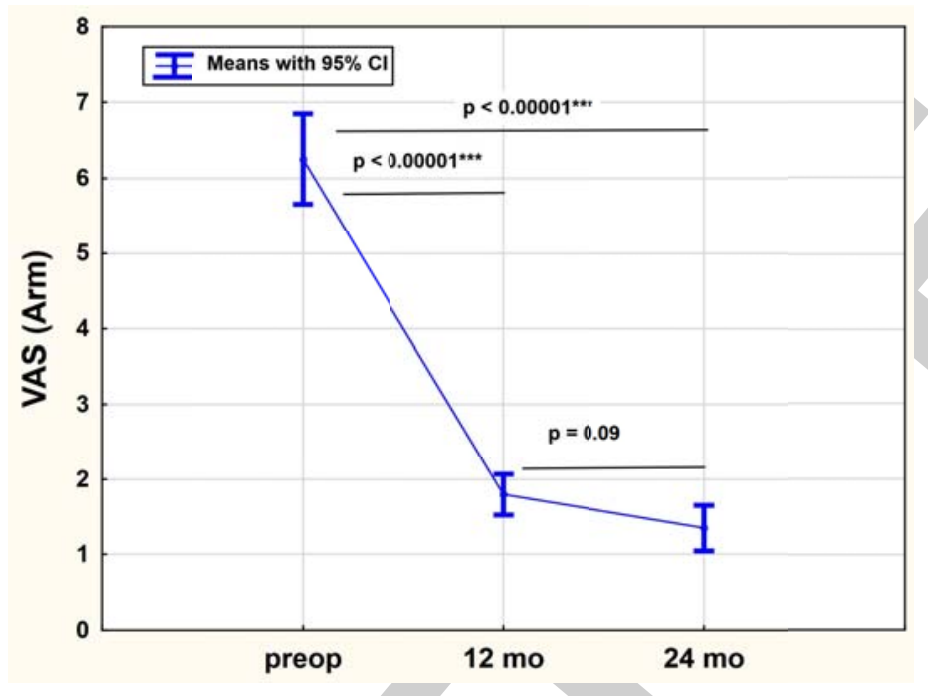

Copyright @ 2018 Wolters Kluwer Health, Inc. Unauthorized reproduction of this article is prohibited. 
Figure 4: Improvement of Visual Analog Scale (VAS) for neck pain over time, illustrated as Whisker plots with 95\% confidence intervals.

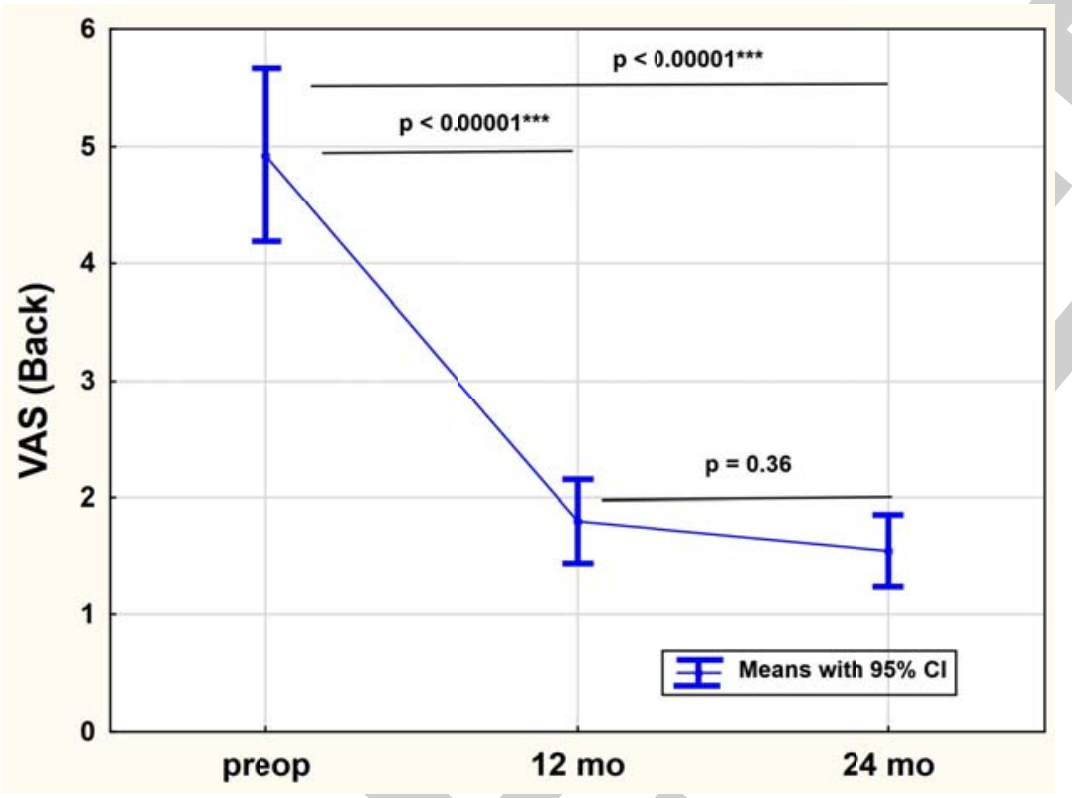

Copyright @ 2018 Wolters Kluwer Health, Inc. Unauthorized reproduction of this article is prohibited. 
Figure 5: Range of Motion (ROM) of the index level over time, illustrated as Whisker plots with 95\% confidence intervals.

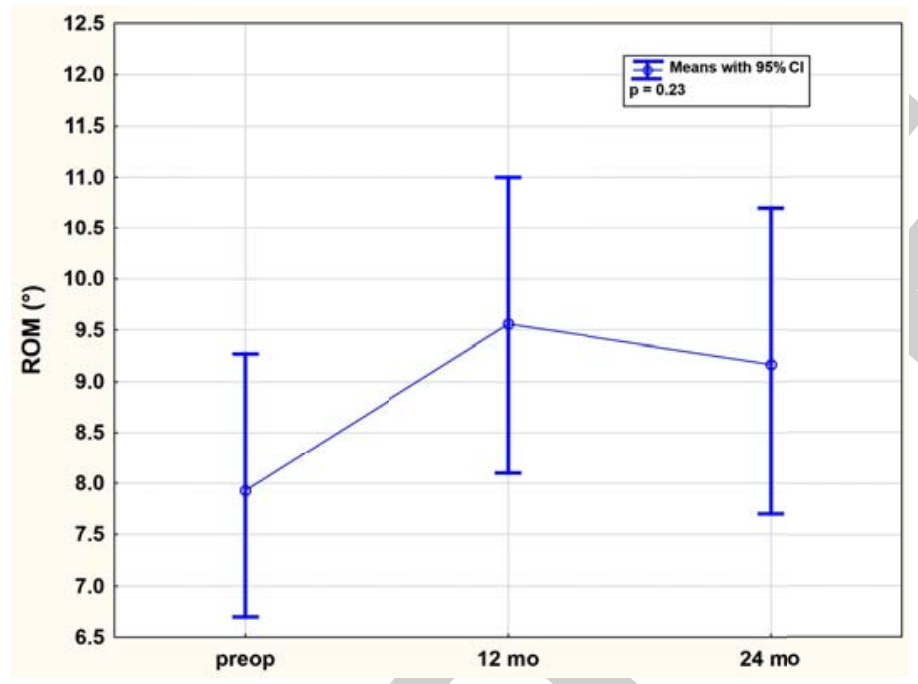

Copyright @ 2018 Wolters Kluwer Health, Inc. Unauthorized reproduction of this article is prohibited. 
Figure 6: Distribution of the incidence of different grades of Heterotopic Ossifications (HO) at the 2 years follow up.

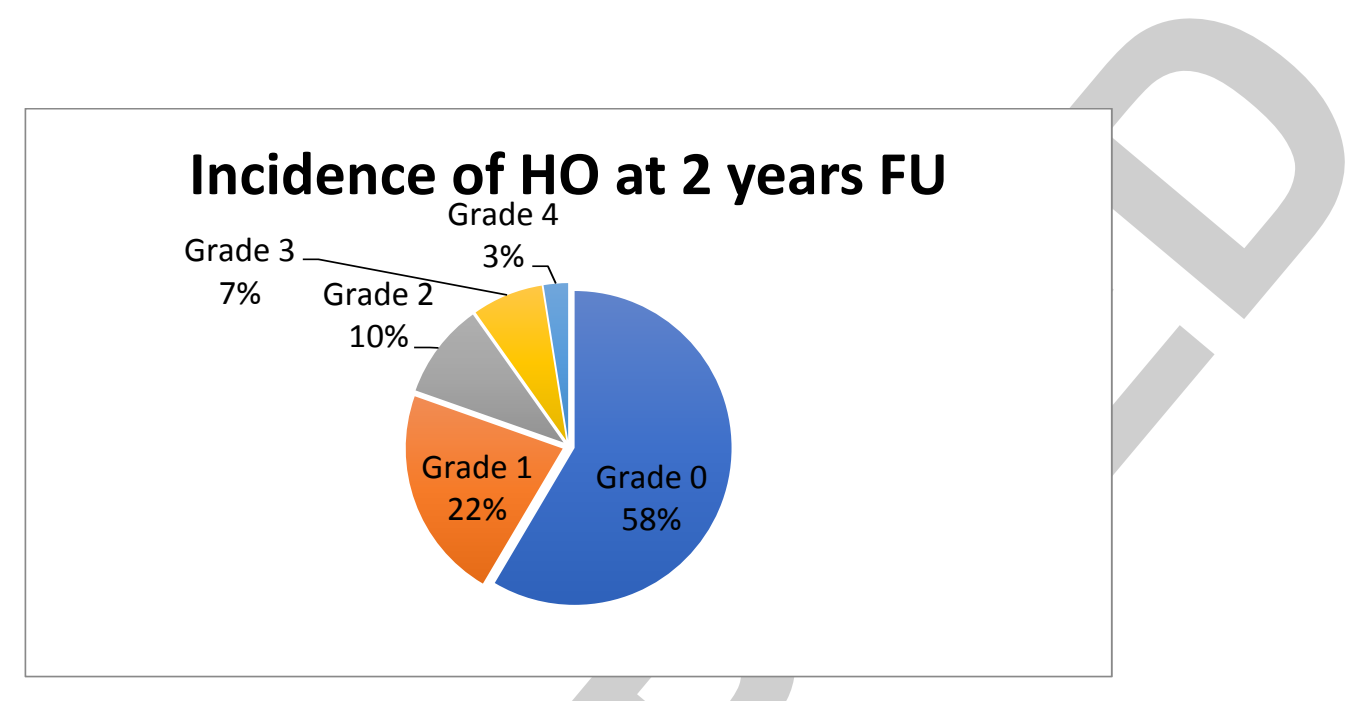

Copyright @ 2018 Wolters Kluwer Health, Inc. Unauthorized reproduction of this article is prohibited. 
Figure 7: Initial positioning of a ProDisc Vivo in C3/4 (A) with consecutive anterior implant dislocation (B). CT scan is demonstrating the insufficient posterior graftbed preparation (C). The radiological result of the revision-surgery with implant removal and fusion with cage (D).
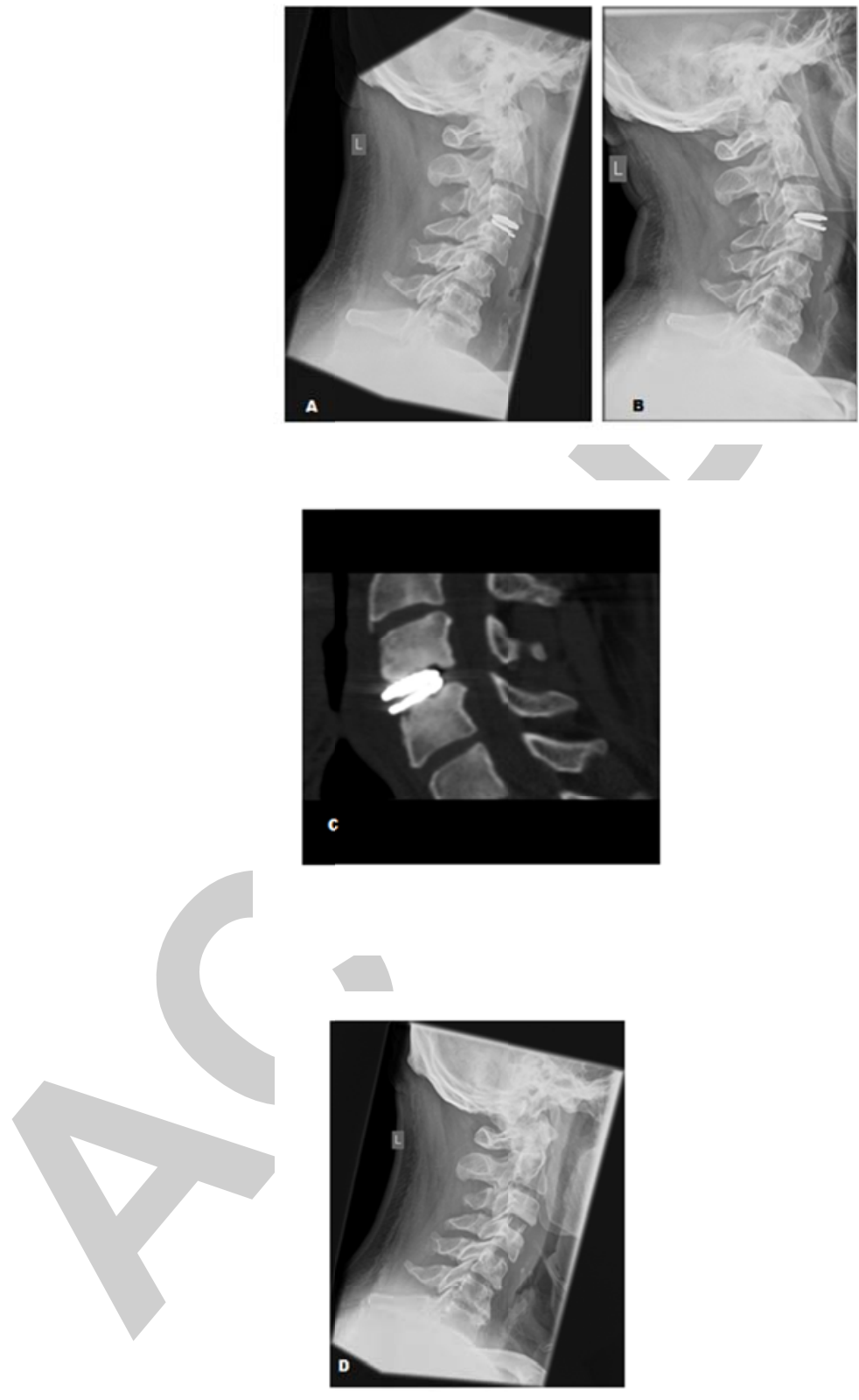

Copyright @ 2018 Wolters Kluwer Health, Inc. Unauthorized reproduction of this article is prohibited. 


\section{Table Legends}

Table 1: Inclusion and exclusion criteria for total cervical disc replacement

Inclusion Criteria

Exclusion Criteria

\begin{tabular}{c||}
\hline \hline Symptomatic cervical disc disease (DDD) \\
\hline Soft disc herniation \\
\hline Cervical spinal stenosis/hard disc \\
\hline Adjacent segment degeneration in fusion
\end{tabular}

Ankylosing spondylitis, rheumatoid arthritis

Infection, tumor

Metabolic bone diseases

\begin{tabular}{c|c}
\hline Degeneration in 1 segment & $\begin{array}{l}\text { Ossification of the posterior longitudinal } \\
\text { ligament (OPLL) or diffuse hyperostosis }\end{array}$ \\
\hline Level C3 - C7 & $\begin{array}{c}\text { Severe osteoarthritis with loss of } \\
\text { intervertebral space height of more than }\end{array}$ \\
$80 \%$
\end{tabular}


Table 2: Characterization of the different grades of heterotopic ossification (HO) in total cervical disc replacement (cTDR)

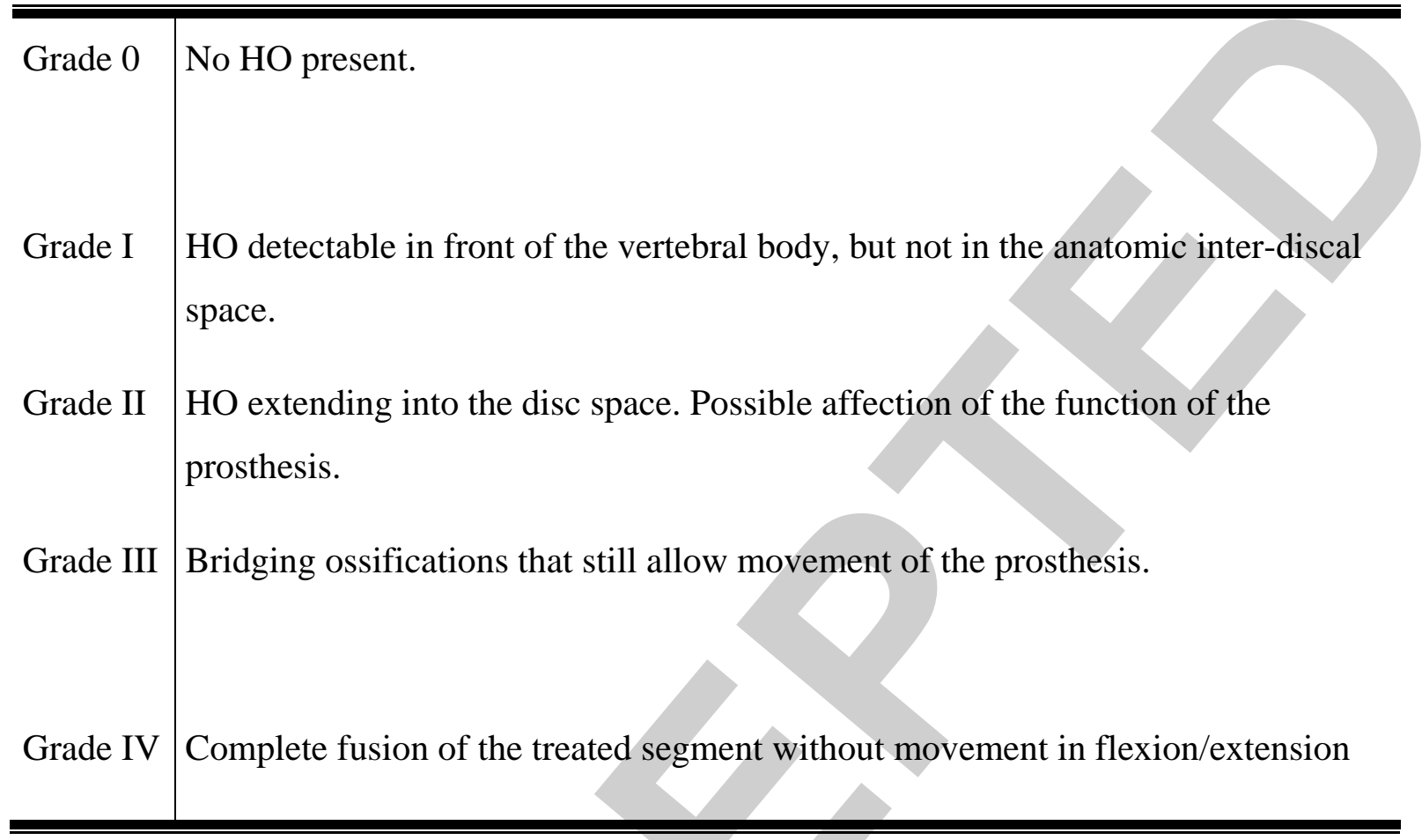

Copyright @ 2018 Wolters Kluwer Health, Inc. Unauthorized reproduction of this article is prohibited. 
Table 3: Patient characteristics

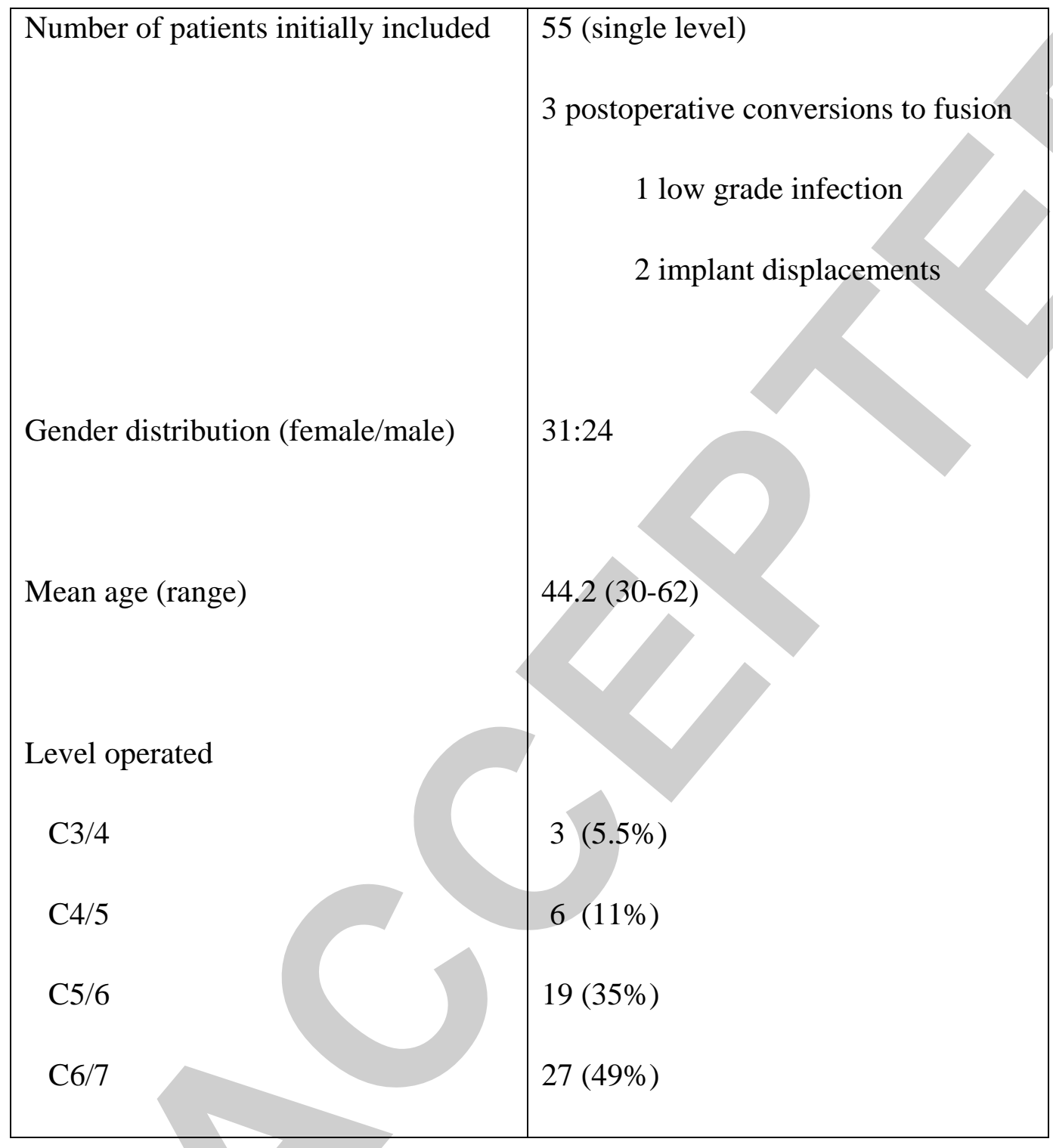

Copyright @ 2018 Wolters Kluwer Health, Inc. Unauthorized reproduction of this article is prohibited. 